\title{
Impact of cataract surgery on visual acuity and quality of life assessed using the National Eye Institute Visual Function Questionnaire 25 in a public teaching hospital in Brazil
}

Impacto da cirurgia de catarata na acuidade visual e na qualidade de vida usando o National Camila Ribeiro Koch ${ }^{1}$ (D), Geórgia de Freitas Neves ${ }^{2}$ (D), Rayane Serrano Paredes² (1), Amanda Ribeiro Araújo de Siqueira² $\mathbb{E}$, Newton Kara-Junior ${ }^{1} \mathbb{1}$

Keywords:

Cataract extraction; VFQ-25;

Visual acuity; Quality of life

Descritores:

Extração de catarata; VFQ-25; Acuidade visual Qualidade de

vida

Received on: Jan 10, 2021

Accepted on: Dec 13, 2021

Corresponding author: Camila Ribeiro Koch Av. Dr. Eneas Carvalho de Aguiar, 255, $6^{\circ}$ andar Zip code 05403000 - São Paulo, SP, Brazil E-mail: oftalmologiacamila@gmail.com

Institution: Institution:
Hospital Humberto Castro Lima, Salvador,
BA, Brazil.

Conflict of interest: no conflict of interest.

Financial support: the authors received no financial support for this work.

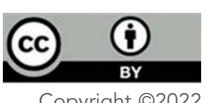

Copyright (C2022

\begin{abstract}
Purpose: This study set out to examine the impact of surgical treatment of senile cataract on visual acuity and quality of life in patients operated in a public teaching hospital.

Methods: Prospective study including patients aged over 60 years with clinical indications for cataract surgery treated at a medical residency service. The National Eye Institute Visual Function Questionnaire 25 was applied. Corrected distance visual acuity was measured before and after cataract surgery. Correlations between National Eye Institute Visual Function Questionnaire 25 scores and corrected distance visual acuity were investigated. Surgeons in charge, and surgical complications were also reported.

Results: A total of 69 patients (89 eyes) were enrolled in this study. Patients were submitted to unilateral (52) or bilateral (17) surgery. Mean patient age was $70.8 \pm 7.3$ (52 to 95) years. Mean preoperative and postoperative National Eye Institute Visual Function Questionnaire 25 scores were $77.4 \pm 15.3$ (25.7 to 98.2) and $89.7 \pm 14.0$ (28.2 to 100) respectively. The larger differences in National Eye Institute Visual Function Questionnaire 25 subscale scores were associated with general vision (from 34.4 to 48.6). Mean preoperative and postoperative corrected distance visual acuity were $0.7 \pm 0.39$ (0.3 to 1.3) LogMAR and $0.24 \pm 0.19$ ( 0.1 to 1.0 ) LogMAR respectively. Comparative analysis of preoperative and postoperative findings revealed significant $(p<0.001)$ improvements in quality of life and corrected distance visual acuity. Most surgeries (70\%, 74 eyes) were performed by surgeons in training. Comparative analysis between patients submitted to unilateral and bilateral surgery revealed significantly $(p=0.016)$ larger visual acuity gains in patients requiring surgery in both eyes. However, questionnaire scores did not differ significantly $(p=2.48)$. Complications were observed in 13 eyes $(14.6 \%)$, posterior capsule tear being the most common. Even in these cases, total National Eye Institute Visual Function Questionnaire 25 scores and corrected distance visual acuity increased significantly $(p<0.001)$.
\end{abstract}

Conclusion: Cataract surgery performed in teaching hospital settings improved patient quality of life and visual acuity. Therefore, public health agencies should ensure access to cataract surgery.

\section{RESUMO}

Objetivo: Avaliar o efeito da cirurgia de catarata na acuidade visual e na qualidade de vida em adultos submetidos à cirurgia de catarata em hospital público de ensino.

Métodos: Estudo prospectivo, que incluiu pacientes acima de 60 anos com indicação clínica para cirurgia de catarata em um serviço de residência médica. O National Eye Institute Visual Function Questionnaire 25 foi aplicado, e a acuidade visual corrigida à distância foi avaliada antes e após a cirurgia de catarata. Foram realizadas correlações entre o escore do National Eye Institute Visual Function Questionnaire 25 e a acuidade visual. Cirurgiões e complicações cirúrgicas também foram descritos.

Resultados: Foram incluídos neste estudo 89 olhos de 69 pacientes, em um total de 52 cirurgias unilaterais e 17 bilaterais. A idade média foi de 70,8 77,3 anos (52 a 95), e a pontuação média do National Eye Institute Visual Function Questionnaire 25 antes da cirurgia foi 77,4 $15,3(25,7$ a 98,2) e, depois, de $89,7 \pm 14,03$ (28,2 a 100). A maior diferença entre os subdomínios do National Eye Institute Visual Function Questionnaire 25 foi a visão geral $(34,4$ a 48,6). A acuidade visual corrigida à distância média antes do

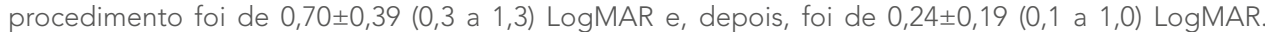
Comparando os resultados antes e após a cirurgia de catarata, houve melhora significativa na qualidade de vida $(p<0,001)$ e na acuidade visual $(p<0,001)$. Dentre as cirurgias, $70 \%$ (74 olhos) foram realizadas por cirurgiões em treinamento. A análise comparativa entre os grupos de pacientes de cirurgias unilaterais e bilaterais apresentou um ganho na acuidade visual maior no grupo que operou ambos os olhos, com significância estatística $(p=0,016)$. No entanto, o aumento na pontuação do questionário, observado em ambos os grupos, não representou diferença estatisticamente significante $(p=2,489)$. Complicações 
foram observadas em 13 olhos (14,6\%), sendo a ruptura de cápsula posterior a mais frequente. Mesmo esses pacientes obtiveram aumento no escore total do National Eye Institute Visual Function Questionnaire $25(p<0,001)$ e na acuidade visual corrigida à distância $(p<0,001)$.

Conclusão: A cirurgia de catarata realizada em ambiente hospitalar de ensino proporciona melhora na qualidade de vida e na acuidade visual, sendo fundamental que os órgãos de saúde pública garantam o acesso da população a esse procedimento.

\section{INTRODUCTION}

Senile cataract is an important cause of visual impairment in individuals aged over 60 years. ${ }^{(1,2)}$ Loss of visual ability has negative impacts on quality of life due to occupational, economic, social, and psychological limitations, which make activities of daily living difficult for patients. The assessment of health-related quality of life is becoming increasingly important, since life expectancy continues to increase. ${ }^{(3)}$ Phacoemulsification, the gold standard approach for cataract removal, allows effective visual rehabilitation, particularly when performed by experienced surgeons. ${ }^{(4,5)}$ This surgical procedure is part of many medical education programs in the major ophthalmology centers worldwide. ${ }^{(6)}$ However, the risk of surgical complications associated with inappropriate medical training is high. $\left.{ }^{7}, 8\right)$

Several instruments have been designed for visual function quantification and quality of life assessment.(9) Visual acuity (VA) measurement during routine ophthalmologic examination aims to quantify vision but does not address relationships with activities of daily living and quality of life. ${ }^{(10,11)}$ The National Eye Institute Visual Function Questionnaire 25 (NEI-VFQ-25) was specifically designed to assess the impact of visual disorders on general health and quality of life. ${ }^{(2,13)}$ Given the importance of providing a better quality of life for elderly patients submitted to cataract surgery, this study set out to investigate correlations between VA and quality of life improvement as per the NEI-VFQ-25 in patients submitted to cataract surgery in a teaching hospital.

\section{METHODS}

This study was performed at Hospital Humberto Castro Lima in Salvador (BA, Brazil) between January $1^{\text {st }}$ and August $30^{\text {th }}$ 2018. Consecutive patients aged over 60 years who had been referred for cataract surgery were enrolled. The study was carried out in compliance with the Declaration of Helsinki and approved by the Medical Institutional Review Board of Escola Bahiana de Medicina e Saúde Pública (EBMSP) (Protocol: 064250/2016 CAAE: 57515016.7.0000.5544), located in Salvador. Informed consent was obtained from study participants who underwent cataract surgery.

\section{Study population and data collection}

Eligible patients were submitted to comprehensive preoperative assessment. Data collected included gender, age, level of education and corrected distance VA (CDVA).
Patients with indication for bilateral surgery answered the questionnaire after both eyes had been operated. Patients who were not able to collaborate due to neurological impairment, did not return for the 30-day review or with poor vision prognosis in one eye were excluded. Eyes with CDVA better than 0.3 LogMAR were not submitted to cataract surgery.

Surgical procedures were randomly allocated to one of three groups of surgeons: consultants (more than five years of experience after completion of the cataract fellowship program), fellows (first year after completion of the residency program) and residents (second or third year of the residence program).

\section{Quality of life and visual acuity assessment}

The NEI-VFQ-25 has been validated in the Portuguese language and is widely used to evaluate the outcomes of ophthalmic surgeries. ${ }^{(13)}$ This questionnaire comprises 25 items that measure vision-related quality of life. Questionnaire items are grouped into 11 subscales: general health, general vision, ocular pain, near activities, distance activities, vision-related mental health problems, vision-related functional limitations, dependency on others due to vision-related limitations, driving difficulties, color perception issues and peripheral vision impairment. ${ }^{(13,14)}$

The NEI-VFQ-25 was administered at two different time points to assess quality of life: 5 to 15 days prior to surgery and 30 to 40 days after surgery. The questionnaire was administered at the cataract department of the referral hospital by a resident physician familiar with the NEIVFQ-25. One resident administered all questionnaires before and after surgery. Visual acuity was evaluated by another physician while questionnaires were administered. In order to avoid biases, examiners were blinded to surgeon, surgical complications and other procedure-related data. Corrected distance visual acuity was measured before and after surgery, on the same day of questionnaire administration, using a Snellen chart placed five meters away from the patient and a near vision chart placed 40 cm away from the patient.

\section{Surgical technique}

Pupils were dilated using topical phenylephrine and tropicamide. Operated eyes were treated with topical moxifloxacin 30 minutes before surgery. Anesthesia was 
used for moderate sedation. Topical anesthesia was used in all patients regardless of the surgeon in charge, except in those sensitive or uncooperative, who were submitted to peribulbar block. Topical anesthesia consisted of 0.5\% proparacaine hydrochloride and $0.75 \%$ bupivacaine hydrochloride. Peribulbar blocks were performed using $2 \%$ lidocaine combined with hyalozime $50 \mathrm{IU} / \mathrm{mL}$.

All patients were submitted to standard phacoemulsification. Briefly, a manual temporal incision was made in the clear cornea. The main incision measured $2.75 \mathrm{~mm}$ and the secondary incision $1.2 \mathrm{~mm}$. Trypan blue was used as an adjuvant as needed to improve visualization of the anterior capsule during phacoemulsification. An ophthalmic viscosurgical device (OVD) (OFTVisc 2\%) was injected into the anterior chamber and manual continuous curvilinear capsulorhexis performed using Utrata forceps. Hydrodissection, hydrodelineation, lens phacoemulsification (Infiniti ${ }^{\circledR}$ Vision System, Alcon Laboratories, Inc.) and cortical aspiration were performed. A single-piece foldable intraocular lens (IOL; Acry-Philic-S model, Leedsay Medical Products, São Paulo, SP, Brazil) was implanted into the capsular bag through the main incision using an injector. The OVD was then removed. A three-piece foldable acrylic IOL (Sensar ${ }^{\circledR}$ AR40eo0260 model; Abbott Medical Optics Inc., Santa Ana, CA, USA) was implanted into the ciliary sulcus in patients who developed posterior capsule tear (PCT). Anterior vitrectomy (Infiniti Vitrectomy Probe) was performed when necessary. The corneal incision was sealed using stromal hydration. All surgeries were supervised by a trained ophthalmologist capable of solving any potential intraoperative complications.

\section{Postoperative assessment}

Patients were treated with a combination of antibiotic and steroid eye drops was instilled every four hours for one week. This dose was tapered weekly over the course of the next four weeks. Follow-up was assessments were carried out 1, 7, 15 and 30 days after surgery. The primary outcomes assessed were postoperative complications, CDVA, and quality of life as per the NEI-VFQ-25.

Patients who developed PCT were submitted to routine treatment with non-steroidal, anti-inflammatory eye drops (nepafenac $0.1 \%$ ) three times daily for four weeks and oral prednisolone given at $1 \mathrm{mg} / \mathrm{kg} / \mathrm{day}$, then tapered gradually (10 mg every 5 days). Perioperative subconjunctival triamcinolone injections were also given. These patients were submitted to macular optical coherence tomography (OCT) and ocular ultrasound examinations as needed and seen by a retina specialist.

\section{Statistical analysis}

Consecutive variables were expressed as mean and standard deviation. Categorical variables were expressed using absolute and relative frequencies. Normality of distribution was assessed using the Kolmogorov-Smirnov and the Shapiro-Wilk tests. Mean VA and total pre and postoperative (NEI-VFQ-25?) scores were compared using the dependent $t$-test. Correlations between mean NEI-VFQ-25 and LogMAR chart scores through Pearson's coefficient was verified using the coefficient of determination in statistically significant cases. The student's t-test and oneway analysis of variance (Anova) were used to examine significant associations between sex, age, level of education, mean NEI-VFQ-25 scores and VA. For statistical analysis purposes, only the VA of the operated eye was considered for in unilateral cases. In order to examine associations between CDVA gains and total NEI-VFQ-25 scores, best eye vision acuity was used in patients (17) submitted to bilateral cataract surgery. Statistical analysis was carried out using Statistical Package for the Social Sciences software (SPSS, Inc.), version 19.0 for Windows. A p-value $<0.05$ was considered statistically significant.

\section{RESULTS}

Eighty-nine patients (106 eyes) were included in this study. Sixty-nine patients (86 eyes) were retained in the final analysis. Patients who did not return (for follow-up assessments were contacted by telephone. Of these, three did not respond and 17 opted to be followed in their home towns. Only two of patients who did not return had intraoperative complications. Patients in this sample were aged $70.8 \pm 7.3$ years (52 to 95 years), $44(63.8 \%)$ were women, $17(24.63 \%)$ needed cataract surgery in both eyes and 52 (75,37\%) in one eye only. As to level of education, 16 patients (23.0\%) had no formal education, 39 (57.0\%) had completed elementary school, 13 (19.0\%) had completed high school and only one (1.0\%) had been to university.

\section{Primary outcomes}

Comparative analysis of mean preoperative ( $0.70 \pm 0.39$; 0.3 to 1.3 LogMAR) and postoperative (0.24 \pm 0.19 ; 0.1 to 1.0 LogMAR) CDVA revealed a mean visual function gain of $0.48 \pm 0.43$ LogMAR, i.e., a significant improvement in VA ( $\mathrm{p}<0.001)$.

In patients submitted to unilateral surgery, comparative analysis of mean preoperative (0.64 \pm 0.39 ; 0.54 to 0.75 LogMAR) and postoperative ( $0.26 \pm 0.21 ; 0.12$ to 0.26 LogMAR) CDVA revealed a mean vision function gain of $0.38 \pm 0.18$ (0.50 to 0.27) LogMAR (p<0.001). In bilateral 
cases, comparative analysis of mean preoperative (0.82 \pm 0.38; 0.62-1.01 LogMAR) and postoperative (0.19 \pm 0.14; 0.12 to 0.26 LogMAR) CDVA revealed a mean vision function gain of $0.63 \pm 0.41$ ( 0.84 to 0.42$)(p<0.001)$. Intergroup comparisons (patients undergoing unilateral or bilateral surgery) revealed a significantly $(\mathrm{p}=0.016)$ larger VA gain in patients who required surgery in both eyes. However, the increase in questionnaire scores did not differ significantly between groups $(\mathrm{p}=2.48)$, findings are shown in Table 2).

Scores assigned to NEI-VFQ-25 subscales also increased. Comparative analysis of mean preoperative (77.4 $\pm 15.3 ; 73.7$ to 81.1$)$ and postoperative ( $89.7 \pm 14 ; 86.3$ to 93.1) NEI-VFQ-25 scores revealed an increase of $12.3 \pm 15.5$ units, indicating statistically significant gains (8.6 to 16.0; $\mathrm{p}<0.001$ ) (Table 1). Score differences were larger in the following subscales: general vision, role limitations and difficulty with distance vision activities (gains of $32.2 \pm$ 28.5, $21.0 \pm 34.5$ and $18.2 \pm 20.5$; $95 \%$ confidence intervals/95\%CI: $25.3-39.0,12.7-29.3$ and $13.2-23.1$ respectively; p <0.001). Only in two out of 12 subscales (ocular pain and driving difficulties) differences were non-significant ( $\mathrm{p}=0.084$ and $\mathrm{p}=0.168$ respectively). Questionnaire scores were also analyzed by groups (patients submitted to bilateral or unilateral surgery). Findings are shown in Table 1.

Table 1. National Eye Institute Visual Function Questionnaire 25 scores and clinical measures of visual function

\begin{tabular}{lccc}
\hline Parameters of all the 69 patients & Preoperative & Postoperative & p-value \\
\hline NEI-VFQ-25 & & & \\
General health & $34 \pm 25$ & $48 \pm 25$ & 0.001 \\
General vision & $36 \pm 17$ & $69 \pm 24$ & $<0.001^{*}$ \\
Ocular pain & $82 \pm 20$ & $86 \pm 18$ & 0.084 \\
Near-vision difficulty & $73 \pm 25$ & $90 \pm 18$ & $<0.001^{*}$ \\
Distant-vision difficulty & $72 \pm 22$ & $90 \pm 18$ & $<0.001^{*}$ \\
Social limitations & $92 \pm 18$ & $98 \pm 9$ & 0.040 \\
Functional limitations & $71 \pm 32$ & $94 \pm 19$ & $<0.001^{*}$ \\
Dependency on others & $85 \pm 23$ & $94 \pm 17$ & 0.016 \\
Driving difficulties & $62 \pm 43$ & $38 \pm 48$ & 0.168 \\
Color vision difficulties & $89 \pm 20$ & $95 \pm 15$ & 0.015 \\
Peripheral vision difficulties & $87 \pm 24$ & $96 \pm 15$ & 0.007 \\
Total score & $77.4 \pm 15.3$ & $89.7 \pm 14.0$ & $<0.001^{*}$ \\
CDVA (LogMAR) & $0.70 \pm 0.39$ & $0.24 \pm 0.19$ & $<0.001^{*}$ \\
Bilateral surgery (17 patients) & & & \\
Total NEI-VFQ-25 score & $71.8 \pm 19.1$ & $88.7 \pm 17.1$ & $\mathrm{p}<0.001$ \\
CDVA (LogMAR) & $0.82 \pm 0.38$ & $0.19 \pm 0.14$ & $\mathrm{p}<0.001$ \\
Unilateral surgery (52 patients) & & & $\mathrm{p}<0.001$ \\
Total NEI-VFQ-25 score & $79.2 \pm 13.6$ & $90.0 \pm 13.1$ & $\mathrm{p}<0.001$ \\
\hline CDVA (LogMAR) & $0.64 \pm 0.39$ & $0.26 \pm 0.21$ & \\
\hline Results expressed as mean \pm standard deviation. & & & \\
* significant difference. & & & \\
NEI-VFQ-25: National Eye Institute Visual Functioning Questionnaire-25; CDVA: corrected distance visual acuity
\end{tabular}

The increase in overall NEI-VFQ-25 scores was significantly correlated with VA improvement $(\mathrm{r}=-0.25 ; \mathrm{p}=0.04)$. The coefficient of determination of the linear regression generated by this correlation suggested limited impacts of CDVA on total NEI-VFQ-25 scores after cataract surgery $\left(r^{2}=0.061\right)$. Age, sex and level of education were not significantly associated $(\mathrm{p}=0.74, \mathrm{p}=0.41$ and $\mathrm{p}=0.05$ respectively) with NEI-VFQ-25 score increase. Pre and postoperative findings are summarized in Figures 1 and 2.

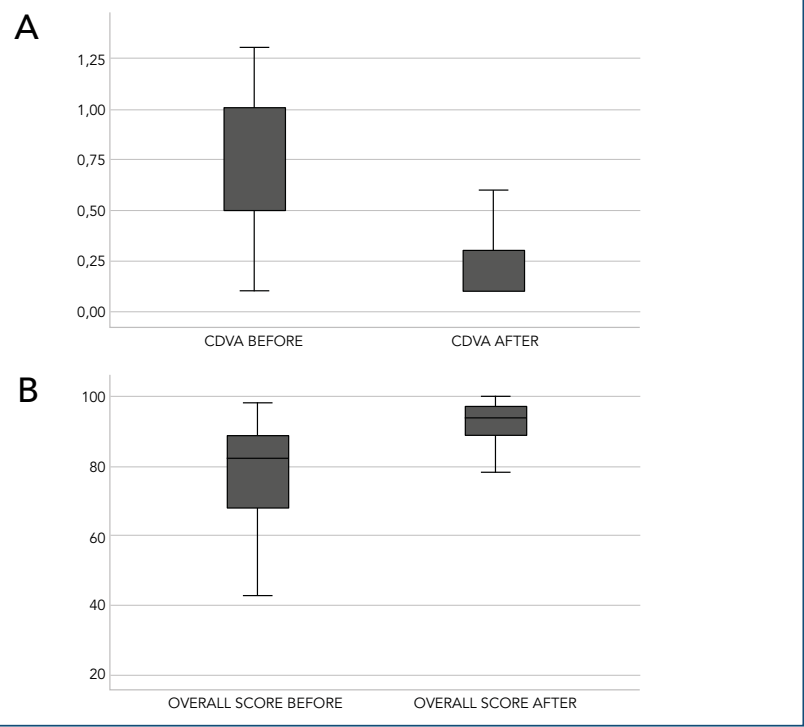

Figure 1. Box plot showing $(A)$ corrected distance visual acuity (LogMAR) and (B) overall score on the National Eye Institute Visual Functioning Questionnaire 25 before and after cataract surgery. Horizontal bars represent the median, the first and the third quartiles. Vertical bars represent the standard deviation of the mean.

\section{Surgeons and complications}

In this sample, 37\% (32 eyes) of surgeries were performed consultants, 38\% (33 eyes) by fellows and 35\% (21 eyes) by residents. Visual acuity gains in patients operated on by consultants, fellows or residents were $0.42 \pm 0.40$ (0.28 to 0.57 ), $0.40 \pm 0.43$ (0.24 to 0.55 ) and $0.68 \pm 0.43$ (0.47 to 0.87$)$ LogMAR respectively, with significant differences between measures ( $\mathrm{p}=0.047$ ). NEI-VFQ-25 scores increased in all cases but did not differ significantly $(\mathrm{p}=0.155)$. Mean preoperative and postoperative CDVA corresponded to $0.55 \pm 0.40$ (0.1 to 1.3) LogMAR and 0.33 \pm 0.30 (0.0 to 1.0) LogMAR respectively.

Complications were observed in 13 eyes (14.6\%). Of these, 11 had PCT, one developed choroidal detachment and one developed cystoid macular edema. The most common complication was PCT (11 eyes; six operated by fellows, three by residents and two by consultants). In these patients, the IOL was implanted into the ciliary sulcus and anterior vitrectomy combined with cataract 


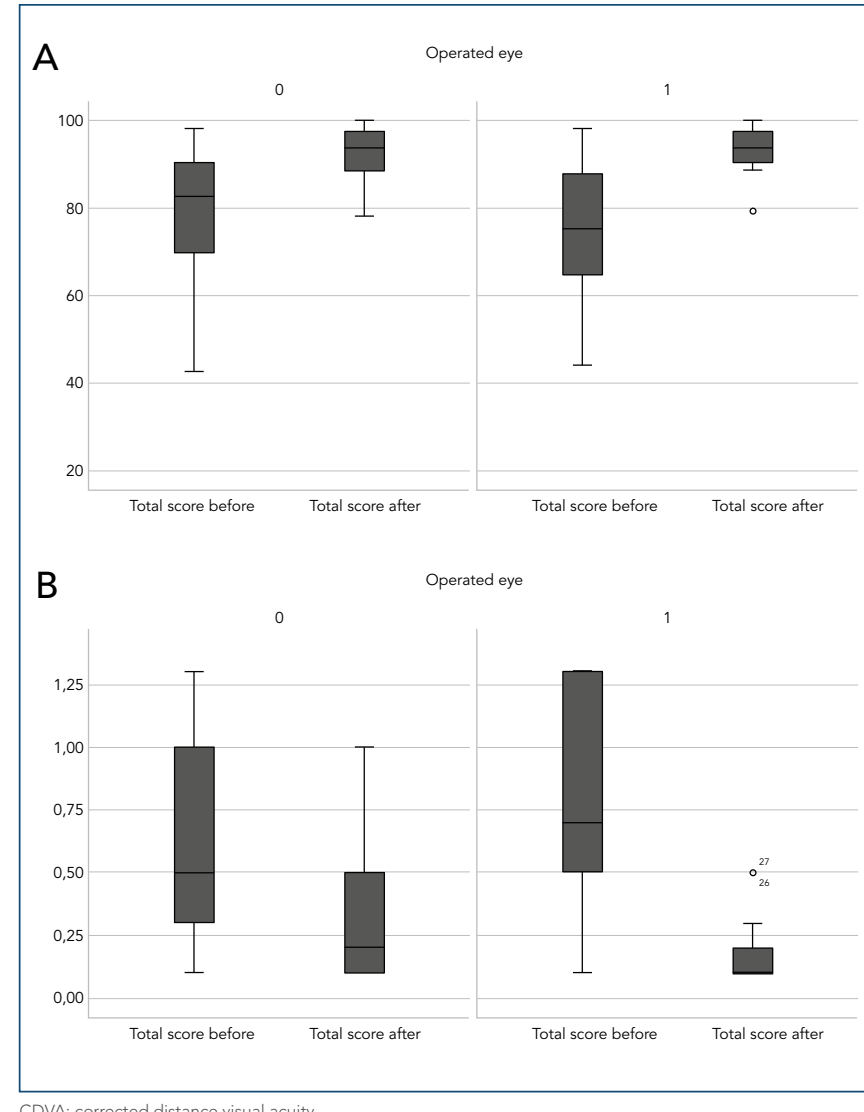

Figure 2. Box plot showing (A) overall score on the National Eye Institute Visual Functioning Questionnaire 25 before and after cataract surgery in unilateral and bilateral cases. (B) Corrected distance visual acuity (LogMAR) before and after cataract surgery in unilateral and bilateral cases. Horizontal bars represent the median, the first and the third quartiles. Vertical bars represent the standard deviation of the mean. Patients submitted to unilateral and bilateral surgery are represented by the numbers zero and 1 .

surgery was needed in five eyes. The eye with traumatic cataract and zonular dehiscence was operated on by a consultant. This eye progressed to choroidal detachment and VA did not improve. A larger number of visits and ocular ultrasound were required for closer monitoring in this case. Atropine 1\% and topical steroids (prednisolone acetate $1 \%$ ) were prescribed for 30 days. One patient developed cystoid macular edema. This patient had been operated on by a fellow and required more frequent visits and serial macular OCT. Nonsteroidal anti-inflammatory eye drops (nepafenac 0,1\%) were prescribed for 60 days. In these cases, CDVA remained at 0.1 LogMAR before and after surgery and no additional surgical procedures were required. Even in cases with complications, VA improved by $0.36 \pm 0.43 \operatorname{LogMAR}(\mathrm{p}=0.01)$. Mean total NEI-VFQ-25 score increased from 73.53 to $77.75(\mathrm{p}=0.42)$ after surgery. However, score differences were non-significant.
Table 2. Comparative analysis of unilateral and bilateral surgeries

\begin{tabular}{lccc} 
Parameters & Mean & Standard deviation & p-value \\
$\begin{array}{lccc}\text { CDVA (LogMAR) } \\
\quad \text { Unilateral }\end{array}$ & 0.383 & 0.414 & 0.0165 \\
$\quad$ Bilateral & $36 \pm 17$ & $69 \pm 24$ & 0.0119 \\
$\begin{array}{l}\text { Total NEI-VFQ-25 score } \\
\quad \text { Unilateral }\end{array}$ & & \\
$\quad$ Bilateral & 10.81 & 15.63 & 2.489 \\
\hline CDVA: corrected distance visual acuity; NEI-VFQ-25: National Eye Institute Visual Functioning Questionnaire-25.
\end{tabular}

\section{DISCUSSION}

The assessment of vision-related functional impairment is critical. ${ }^{(15,16)}$ Visual acuity is an extremely useful and fast user-friendly tool. However, this tool alone is not enough to measure all requirements and postoperative outcomes of cataract surgery. The NEI-VFQ-25 is widely used to examine the impact of ocular diseases on quality of life. ${ }^{(17)}$ This study revealed significant improvements in the quality of life of patients operated on due to senile cataract in a medical residence program. Increase in overall NEI-VFQ-25 scores after surgical treatment and significant gains in most NEIVFQ-25 subscales suggest cataract surgery is beneficial not only with regard to activities of daily living, but also to social and mental health. ${ }^{(18)}$

A major concern in patients with senile cataract is the impact of the disease on their ability to perform activities of daily living. Findings obtained using the NEIVFQ-25 and similar visual functioning assessment tools suggest the impact of cataract surgery extend beyond VA. ${ }^{(19,20)}$ These instruments provide convincing evidence that vision enhancement in response to cataract surgery is associated with improvements in several activities of daily living. ${ }^{(21,22)}$ In this study, VA improved significantly after surgical treatment of senile cataract. However, the fact that only $6.1 \%$ of the variability in total NEI-VFQ-25 scores can be explained by VA suggests cataract surgery promotes well-being as well as VA improvement. Prior studies have shown that administration of the NEI-VFQ-25, which measures vision-related limitations, appears to be an appropriate strategy to assess the outcomes of cataract surgery. . $^{(9-23)}$

The patients in this study were allocated to different groups for assessment of VA and quality of life changes after cataract surgery. Comparative analysis revealed that, although patients submitted to bilateral surgery achieved better VA outcomes, quality of life improvement was similar in both groups.

Correlations between quality of life and VA in patients operated on at a medical training service have not been reported to date. In this study, patients undergoing 
surgery in a public teaching hospital achieved a 12.3-unit increase in total NEI-VFQ-25 scores. These findings support the application of NEI-VFQ-25 to measure gains in visual functioning.

Statistically significant gains were also observed in most NEI-VFQ-25 subscales, including general health (14unit gain), near vision (15-unit gain), distance vision (18unit gain), functional limitations (21-unit gain), dependency on others (six units), social limitations (four units), peripheral vision (seven units, and color vision (five units). These outcomes suggest quantitative improvements in several aspects of life in individuals submitted to cataract surgery, such as social interaction, mental and emotional well-being, and are in keeping with findings reported by Oshika et al. ${ }^{(24)}$ However, ocular pain and driving difficulties did not improve significantly after cataract surgery in this study. In the driving difficulties subscale, lack of improvement may be explained by the fact that most of patients in this sample did not drive. As to ocular pain, authors recommend the application of specific assessment scales, since subjective symptoms are difficult to measure using the NEI-VFQ-25.

The rate of surgical complications was similar in this and prior studies. ${ }^{(6,7,25,26)}$ This study has some limitations. Overall, 22.1\% of patients were lost to follow-up. Most of these patients lived in the countryside, far away from the hospital, and could be more easily monitored in ophthalmology services closer to their homes. Although the underlying reason for loss to follow-up is unclear, it may have been due to postoperative improvement and lack of major complications, as only two patients had perioperative complications. The value of this study stems from the fact that it is the first to examine the quality of vision and demonstrate gains in quality of life after cataract surgery in patients operated by physicians undergoing training in a teaching hospital.

The positive impact of cataract surgery on quality of life translates into considerable improvements in performance of activities of daily living, as well as in social and emotional aspects. Therefore, surgical treatment of senile cataract is highly recommended. Findings of this study may be applicable to other teaching settings and may encourage public health agencies to ensure access to cataract treatment in medical teaching hospitals for elderly patients.

\section{ACKNOWLEDGMENTS}

This study was partially financed by the Coordination for Improvement of Higher Education Personnel (CAPES).

\section{REFERENCES}

1. Flaxman SR, Bourne RR, Resnikoff S, Ackland P, Braithwaite T, Cicinelli $M V$, et al.; Vision Loss Expert Group of the Global Burden of Disease Study. Global causes of blindness and distance vision impairment 1990-2020: a systematic review and meta-analysis. Lancet Glob Health. 2017;5(12):e1221-34.

2. Lansingh VC, Carter MJ, Martens M. Global cost-effectiveness of cataract surgery. Ophthalmology. 2007;114(9):1670-8.

3. Luiz LC, Rebelatto JR, Coimbra AM, Ricci NA. Associação entre déficit visual e aspectos clínico-funcionais em idosos da comunidade. Rev Bras Fisioter. 2009 [citado 202124 Set. 2021];13(5):444-50. Disponível em: https://www. scielo.br/j/rbfis/a/M9QS6SJNP6Z8wHCQJSGvhxH/?format=pdf\&lang=pt

4. Goldberg DG, Goldberg MH, Shah R, Meagher JN, Ailani H. Pseudophakic mini-monovision: high patient satisfaction, reduced spectacle dependence, and low cost. BMC Ophthalmol. 2018;18(1):293.

5. Zhu B, Ma Y, Lin S, Zou H. Vision-related quality of life and visual outcomes from cataract surgery in patients with vision-threatening diabetic retinopathy: a prospective observational study. Health Qual Life Outcomes. 2017;2;15(1):175.

6. Barreto Júnior J, Primiano Júnior H, Espídola RF, Germano RA, Kara-Júnior N. Cirurgia de catarata realizada por residentes: avaliação dos riscos. Rev Bras Oftalmol. 2010;69(5):301-5.

7. Araújo ME, Chou AC, Silva CR, Oliveira LB, Neustein I. Facoemulsificação: resultados e complicações nos primeiros 100 olhos. Arq Bras Oftalmol. 2000;63(1):29-31.

8. Yu AY, Wang QM, Li J, Huang F, Golnik K. A cataract surgery training program: 2-year outcome after launching. J Surg Educ. 2016;73(5):761-7.

9. Lamoureux EL, Fenwick E, Pesudovs K, Tan D. Impact of cataract surgery on quality of life. Curr Opin Ophthalmol. 2011;22(1):19-27.

10. Simão LM, Lana-Peixoto MA, Araújo CR, Moreira MA, Teixeira AL. The Brazilian version of the 25-Item National Eye Institute Visual Function Questionnaire: translation, reliability and validity. Arq Bras Oftalmol. 2008;71(4):540-6

11. Pinheiro DP, Rosa ML, Velarde LG, Lomelino JP, Knopp PE, Ventura MP. Quality of life in glaucoma patients: comparison between public health system and private practice. Rev Bras Oftalmol. 2010;69(6):378-82.

12. Lau J, Michon JJ, Chan WS, Ellwein LB. Visual acuity and quality of life outcomes in cataract surgery patients in Hong Kong. Br J Ophthalmol. 2002;86(1):12-7

13. Mangione CM, Lee PP, Gutierrez PR, Spritzer K, Berry S, Hays RD; National Eye Institute Visual Function Questionnaire Field Test Investigators. Development of the 25-item national eye institute visual function questionnaire. Arch Ophthalmol. 2001;119(7):1050-8.

14. Kovac B, Vukosavljevic M, Djokic Kovac J, Resan M, Trajkovic G, Jankovic $J$, et al. Validation and cross-cultural adaptation of the National Eye Institute Visual Function Questionnaire (NEI VFQ-25) in Serbian patients. Health Qual Life Outcomes. 2015;13:142.

15. Steinberg EP, Tielsch JM, Schein OD, Javitt JC, Sharkey P, Cassard SD, et al. The VF-14. An index of functional impairment in patients with cataract. Arch Ophthalmol. 1994;112(5):630-8.

16. Desai P, Reidy A, Minassian DC, Vafidis G, Bolger J. Gains from cataract surgery: visual function and quality of life. $\mathrm{Br} \mathrm{J}$ Ophthalmol. 1996;80(10):868-73

17. Menezes C, Vilaça KH, Menezes RL. Quedas e Qualidade de vida de idosos com catarata. Rev Bras Oftalmol. 2016;75(1):40-4.

18. Ishii K, Kabata T, Oshika T. The impact of cataract surgery on cognitive impairment and depressive mental status in elderly patients. Am J Ophthalmol. 2008;146(3):404-9.

19. To KG, Meuleners LB, Fraser ML, Do DV, Duong DV, Huynh VA, et al. The impact of cataract surgery on vision-related quality of life for bilateral cataract patients in Ho Chi Minh City, Vietnam: a prospective study. Health Qual Life Outcomes. 2014;12:16.

20. Mendonça PT, Mendonça LT, Rosa AA, Silveira LC. Avaliação da qualidade de vida de pacientes submetidos à facoemulsificação ou extração extracapsular de catarata. Arq Bras Oftalmol. 2014;77(1):12-6. 
21. Ribeiro JE, Freitas MM, Araújo GS, Rocha TH. Associação entre aspectos depressivos e déficit visual causado por catarata em pacientes idosos. Arq Bras Oftalmol. 2004;67(5):795-9.

22. Walker JG, Anstey KJ, Hennessy MP, Lord SR, Sanden CV. The impact of cataract surgery on visual functioning, vision-related disability and psychological distress: a randomized controlled trial. Clin Exp Ophthalmol. 2006;34(8):734-42.

23. Zhang F, Sugar A, Jacobsen G, Collins M. Visual function and spectacle independence after cataract surgery: bilateral diffractive multifocal intraocular lenses versus monovision pseudophakia. J Cataract Refract Surg 2011;37(5):85324.
24. Oshika T, Sugita G, Hayashi K, Euguchi S, Miyagi K, Kozawa T, et al. Influence cataract and intraocular lens surgery no Health-relates quality of life. Nippon Ganka Gakkai Zasshi. 2005;109(11):753-60.

25. Bhagat N, Nissirios N, Potdevin L, Chung J, Lama P, Zarbin MA et al. Complications in resident-performed phacoemulsification cataract surgery at New Jersey Medical School. Br J Ophthalmol. 2007;91(10):1315-7.

26. Fathallah M, Eltanamly RM, Saadeldin H, Elnahry GH. Causes of suboptimal corrected visual acuity following phacoemulsification in a teaching university hospital. Eur J Ophthalmol. 2017;27(2):169-73. 